\title{
Sol gel technique to prepare composite material of glass-dye-polymers
}

\author{
Jayanta K. Ray* and Leena Bhowmik \\ Department of Chemistry, Indian Institute of Technology, Kharagpur -721302, India
}

\begin{abstract}
Herein we describe the synthesis and in-depth characterization of chemically blended hybrid glasses in which polymer molecules are uniformly distributed and covalently bonded to inorganic matrices. This approach uses a monomer with double bonds, which are hydrosilylated with triethoxy silane and co-condensed with silicon tetraalkoxide to afford a molecular composite of $\mathrm{SiO} 2$ glass and the polymer. The generated coposites were characterized using SEM, TGA and $\mathrm{XRD}$ as well as a host of stability tests. They showed increased stability and uniform distribution of the blend.
\end{abstract}

\section{Introduction}

Developments within the area of sol-gel science and technology have led to the proliferation of a vast array of organic-inorganic nano composites. In recent years a large variety of organic and inorganic polymer hybrids have been synthesized by the sol-gel technique utilizing alkoxy silane. A most noticeable characteristic of these hybrid materials is the molecular-level integration of organic and inorganic elements ${ }^{1-3}$. The interactions that have been utilized to integrate phases are generally classified into two groups, covalent bonding and hydrogen bonding interactions. The covalent interaction is attained by incorporation of silane coupling groups into organic segments. This chemistry can lead to high purity, inorganic, monocomponent and multicomponent glasses. It has led to a class of materials that involves the incorporation of a nanoscopic inorganic phase 
into an organic polymer matrix. Polymers and composite materials have thus found applications in various domains ${ }^{4-28}$. Sol processing of alkoxy silanes with organic substituents represents a very attractive route to organic-inorganic hybrid materials. The main advantages of sol-gel process are its mild reaction conditions allowing the combination of a large variety of organic monomers with inorganic precursors like tetraethoxy silane and triethoxy silane. The sol-gel process provides inorganic networks or nano particle with polymerizable organic functions. These hybrid materials offer excellent properties as coating materials or as reactive filler compounds in nano composites. We have discussed the preparation and characterization of colored glasses using organic dyes and pigments. But all such composites were cracked after some days. The capillary pressure arising out of evaporation of organic solvents during drying and aging and mainly responsible for the cracks created in the gel glasses. Any manipulation aimed at the decrease of porosity will efficiently reduce the capillary action.

Furthermore, the direct chemical bonding of organic chains to the $\mathrm{SiO}_{2}$ matrix may help to arrest the cracks, by distribution of the crack propagation energy. This is based on the same mechanism as using the crystal fibers to reinforce the novel ceramic composites. The simultaneous sol-gel condensation of tetraalkoxy silane with polymerizable groups lead to semi-interpenetrating network of linear organic polymer in low density $\mathrm{SiO}_{2}$ network. The use of the tetraethoxy silane is expected to enhance the incorporation of organic moiety by condensation with terminal $\mathrm{O}-\mathrm{H}$ group. During the preparation of chemically blended silica glass initially we choose acrylate monomer so that end groups or pendant groups having olefinic function were converted to $\mathrm{Si}(\mathrm{OEt})_{3}$ by hydrosilylation. Incorporation of organic polymers into inorganic glass matrix via covalent bonding is particularly interesting because the new hybrid material would have a controllable combination of the properties of both organic polymer and inorganic glasses. Many polymers such 
as poly (dimethylxysilane), poly (tetra methylene oxide), polyamide, poly (arylene ether ketone) and poly (arylene ether sulfone) were reported to be incorporated into $\mathrm{SiO}_{2}$ and/or $\mathrm{TiO}_{2}$ glass network $^{29-32}$. At the current stage, most research is concentrated on the synthesis and tailoring the microstructures of the new hybrid material. There are relatively few reports that explore physical properties and application of this material. A very interesting interpenetrating polyacrylate- $\mathrm{SiO}_{2}$ composite was prepared recently by simultaneous formation of the $\mathrm{SiO}_{2}$ sol-gel glass and polyacrylate ${ }^{33-36}$. We have been interested in the synthesis of chemically blended hybrid glasses in which polymer molecules are uniformly distributed and covalently bonded to inorganic matrices ${ }^{37-}$ 39 . In our approach monomer having double bond are hydrosilylated with triethoxy silane and cocondensed with silicon tetraalkoxide to afford a molecular composite of $\mathrm{SiO}_{2}$ glass and the polymer. Inorganic alkoxides are expected to increase the thermal stability of the polymer.

\section{Experimental}

\section{Materials}

Methyl methacrylate (MMA), Napthol and vinyl triethoxy silane were purchased from Fluka. Reagent grade triethoxy silane was purchased from Aldrich. Hydrochloric acid, THF and Alizarin were purchased from EMerck. Chloroplatinic acid $\left(\mathrm{H}_{2} \mathrm{PtCl}_{6}\right)$ was purchased from Aldrich was purchased from Fluka.

\section{Synthesis of inorganic-organic hybrid sol-gel glass}

Monomers having vinyl groups used in this particular work were polymerized via free radical pathway, such as methyl methacrylate, allyl methacrylate, vinyl triethoxysilane. The polymers thus obtained contain end groups or pendants having olifinic functions or trialkoxysilane group respectively. By hydrosilylation, trialkoxysilyl groups were incorporated into the unsaturtated pendants. After this the polymer and tetraethyl orthosilicate (TEOS) were hydrolyzed and condensed by sol-gel technique to produce the chemically bonded hybrid glass. These syntheses are described in different schemes. 


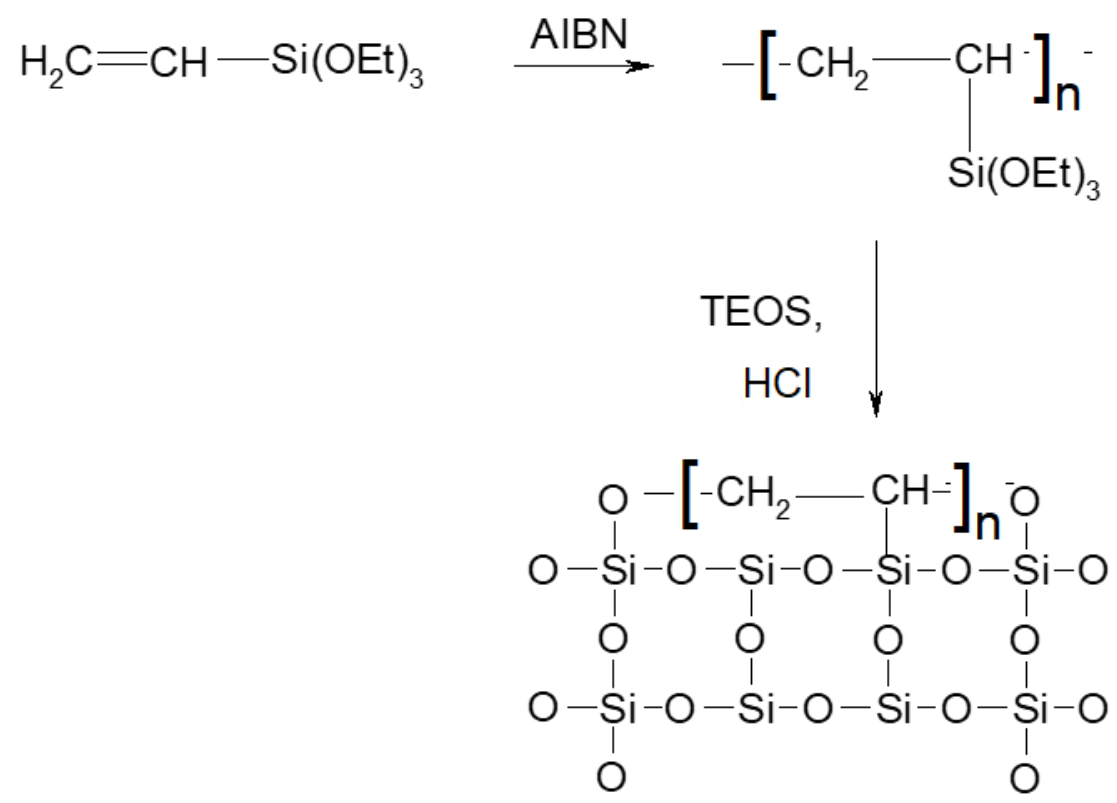

Scheme 1 Vinyl triethoxy silane derived sol-gel glass $\left(\mathrm{VNY}-\mathrm{SiO}_{2}\right)$

\section{Synthesis of Vinyl triethoxy silane derived sol-gel glass (VNY-SiO 2$)$}

A $50 \mathrm{ml}$ round bottom flask was charged with $4 \mathrm{ml}$ vinyl triethoxy silane which was polymerized using AIBN as initiator at $60{ }^{0} \mathrm{C}$ temperature. After that the prepared polyvinyl triethoxy silane was taken in a $50 \mathrm{ml}$ round bottom flask and dissolved in anhydrous THF and $2 \mathrm{ml}$ TEOS were added. Then a catalytic amount of $1 \mathrm{M} \mathrm{HCl}$ and distilled water were added dropwise and stirring 
was continued for $24 \mathrm{~h}$. The solution was then poured in a beaker of $4 \mathrm{~cm}$ diameter and covered with a paraffin film with holes punched into it. After 30 days a silica glass was obtained.

\section{Synthesis of Methyl methacrylate derived sol-gel glass (MMA-SiO $)$}

In a round bottom flask $10 \mathrm{mg}$ of Spier's catalyst $\left(\mathrm{H}_{2} \mathrm{PtCl}_{6}\right)$ was dissolved in dry THF under argon atmosphere. After that $1.25 \mathrm{ml}$ of MMA and $2.3 \mathrm{ml}$ of triethoxysilane were added. Stirring was continued at room temperature. After 30 min of stirring black $\mathrm{PtO}_{2}$ precipitate was separated, which indicated that the completion of reaction. THF was removed by applying vacuum. By column chromatography $\mathrm{PtO}_{2}$ was removed from final hydrosilylated product. Then the prepared hydrosilylated methyl methacrylate was dissolved in dry THF in a $50 \mathrm{ml}$ round bottom flask. $2 \mathrm{ml}$ TEOS was then added along with a, catalytic amount of $1 \mathrm{M} \mathrm{HCl}$ and water and the reaction was continued for $24 \mathrm{~h}$. The solution mixture was then poured in a beaker and allowed to stand at room temperature with a perforated paraffin film cover. The glass was obtained after 20 days of drying.<smiles>C=C(C)C(=O)OC</smiles><smiles>CCO[SiH2]OCC</smiles>

Scheme 2. Synthesis of Methyl methacrylate derived sol-gel glass (MMA-SiO $\left.{ }_{2}\right)$ 


\section{Preparation of 2-Hydroxy-3,4-dihydro-2Hnapthalene-1-one derived sol-gel glass (NAP-SiO 2}

glass)

$0.275 \mathrm{~g}(1.85 \mathrm{~m} \mathrm{~mol}) \mathrm{NaI}$ and $0.152 \mathrm{ml}$ allyl bromide were added to $10 \mathrm{ml}$ acetone solution and stirred for $30 \mathrm{~min}$. Then $0.68 \mathrm{~g}$ of $\mathrm{K}_{2} \mathrm{CO}_{3}$ and $0.30 \mathrm{~g}$ of reagent were added. The mixture was refluxed in a water bath. After $5 \mathrm{~h}$ the reaction mixture was poured into ice-cold water and extracted with diethyl ether. After evaporation of solvent the product was purified by column chromatography.

The allylated product was then hydrosilylated by using Spier's catalyst. $10 \mathrm{mg}$ of Spier' catalyst was dissolved in dry THF solution and argon gas was passed. The solution was stirred for $15 \mathrm{~min}$ to dissolve the catalyst. $1 \mathrm{ml}$ of allylated product and $1.5 \mathrm{ml}$ triethoxy silane were added to the contents of the flask by a syringe. The reaction was exothermic. Stirring was continued for $1 \mathrm{~h}$ under $\mathrm{N}_{2}$ atmosphere. After completion of reaction the solvent was removed under reduced pressure. Then $0.5 \mathrm{ml}$ of hydrosilylated naphthalene derivative was dissolved in $10 \mathrm{ml}$ of dry THF. and $2 \mathrm{ml}$ TEOS, catalytic amount of $1 \mathrm{M} \mathrm{HCl}$ and distilled water were added and stirring was continued overnight. The homogeneous viscous solution was poured in a $50 \mathrm{ml}$ beaker covered with perforated paraffin film and silica glass was obtained after a month.<smiles>O=C1c2ccccc2CCC1O</smiles>
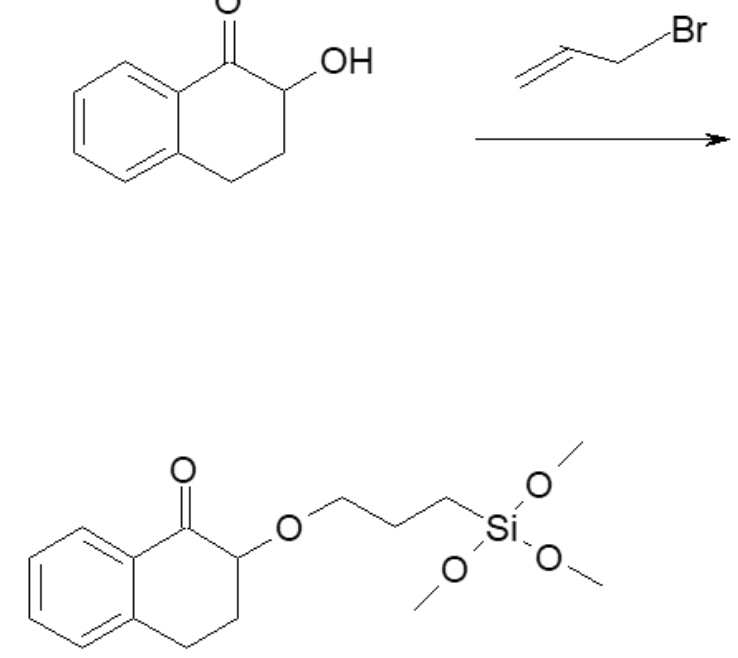

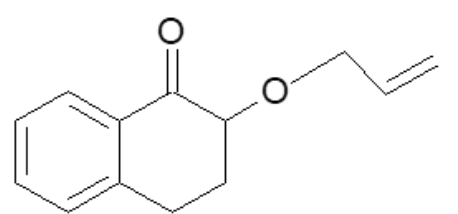

$$
\mid \begin{aligned}
& \mathrm{HSi}(\mathrm{OEt})_{3} \\
& \mathrm{H}_{2} \mathrm{PtCl}_{6}
\end{aligned}
$$

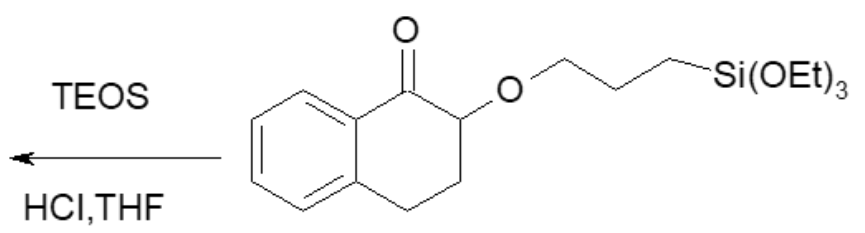

Scheme 3. Synthesis of Hydroxy-3,4-dihydro-2Hnapthalene-1-one derived sol-gel glass (NAP$\mathrm{SiO}_{2}$ glass 


\section{Synthesis of Alizarin derived sol-gel glass (Chem-Ali-SiO $\left.{ }_{2}\right)$}

A mixture of $0.52 \mathrm{~g}(3.0 \mathrm{~m} \mathrm{~mol})$ of $\mathrm{NaI}$ and $0.23 \mathrm{ml}$ of allyl bromide were dissolved in dry acetone in a $10 \mathrm{ml}$ round bottom flask and stirred for $30 \mathrm{~min}$. After that around $1.3 \mathrm{~g}$ of $\mathrm{K}_{2} \mathrm{CO}_{3}$ was added followed by the addition of $0.36 \mathrm{~g}(1.5 \mathrm{~m} \mathrm{~mol})$ of alizarin. The mixture was refluxed for $8 \mathrm{~h}$. The reaction mixture was then poured into ice-cold water and extracted with diethyl ether. The yellow solid was obtained after evaporation of solvent and subjected to column chromatography using benzene-petroleum ether. The desired product was obtained as the first elute. The solvent was removed by applying vacuum and dried.

Then $0.40 \mathrm{~g}$ bis-O-allyl alizarin $(1.25 \mathrm{~m} \mathrm{~mol})$ was dissolved in $1 \mathrm{ml}$ dry THF. To this solution $0.02 \mathrm{~g}$ of $\mathrm{H}_{2} \mathrm{PtCl}_{6}$ and triethoxy silane were added. Stirring was continued in nitrogen atmosphere for $1 \mathrm{~h}$. After completion of the reaction the solvent was removed in vacuo. By column chromatography $\mathrm{PtO}_{2}$ was removed from the hydrosilylated product.

A $50 \mathrm{ml}$ round-bottomed flask was charged with a solution of bis hydrosilylated alizarin in THF. Then $2 \mathrm{ml}$ of TEOS was added and stirred at room temperature. Required amount of $\mathrm{HCl}$ and distilled water were added, and the reaction was continued for $24 \mathrm{~h}$. The solution was then poured in a beaker and allowed to stand at room temperature with a perforated paraffin film cover. The glass was obtained after few days of drying. 
<smiles>O=C1c2ccccc2C(=O)c2c1ccc(O)c2O</smiles><smiles>C=CCBr</smiles><smiles>C=CCOc1ccc2c(c1OCC=C)C(=O)c1ccccc1C2=O</smiles><smiles></smiles><smiles>CCO[SiH2]CCCOc1ccc2c(c1OCCC[SiH2]OCC)C(=O)c1ccccc1C2=O</smiles>

Scheme 4. Synthesis of Alizarin derived sol-gel glass (Chem-Ali-SiO 2$)$

\section{FTIR and NMR spectroscopic analysis}

Infrared absorption spectra were recorded between $400-4000 \mathrm{~cm}^{-1}$ by Fourier transform infrared spectrophotometer (FTIR) (Perkin-Elmer).

\section{Thermal stability}

Thermal analysis (TG-DTA) of the silica composite was done on a Shimadzu DT-40 unit, under $\mathrm{N}_{2}$ atmosphere. A heating rate of $10^{\circ} \mathrm{C} \mathrm{min}-{ }^{1}$ was used.

\section{Scanning electron microscopic analysis}

Scanning electron micrographs of the polymer samples was taken on a Cam Scan 2DV unit.

\section{Hydrolytic stability}

In order to study the water absorption behavior, the chemically blended silica composite was cut into small pieces. Before testing, the specimens were dried in an oven at $30{ }^{\circ} \mathrm{C}$ for $2 \mathrm{~h}$ and kept over fused $\mathrm{CaCl}_{2}$ for $24 \mathrm{~h}$. Then the initial weights $\left(\mathrm{W}_{1}\right)$ of the samples were measured. After that these samples were immersed in distilled water and after 7 days of immersion the specimens were taken out and wiped well with filter paper. The swelled weight $\left(\mathrm{W}_{2}\right)$ was measured again carefully and water absorption was calculated using the following relation.

$\%$ Water absorption $=\left[\mathrm{W}_{2}-\mathrm{W}_{1}\right] / \mathrm{W}_{1} \times 100$

\section{Stability in acid}


In order to measure the stability of the composite samples prepared by above mentioned method in acid medium we used $10^{-6} \mathrm{M} \mathrm{HCl}$. Before testing all the prepared specimens were kept over fused $\mathrm{CaCl}_{2}$ for $24 \mathrm{~h}$ followed by measurements of weights $(\mathrm{X})$ of all the samples. Then the specimens were immersed in $\mathrm{HCl}$ solution. After definite time of interval specimen were taken out and washed thoroughly with distilled water to remove traces of acid, if any. Then the specimens were dried carefully before measuring the final weight. The final weight of the samples was measured (Y). Any decrease or increase in weight of the glass specimen was calculated by using the following relation. From this value we can know whether any decomposition or any change takes place or not due to the action of acid.

$\%$ Weight loss $=[\mathrm{X}-\mathrm{Y}] / \mathrm{X} \times 100$

\section{X-Ray diffraction analysis}

XRD profiles were recorded on a Philips PW-1840 x-ray diffractometer using Cu K $\alpha$ radiation of wavelength $0.154 \mathrm{~nm}$. The instrument was operated at $40 \mathrm{KV}$ and $20 \mathrm{~mA}$. The powdered samples were pressed in a square plastic sample holder, which had $1 \mathrm{~mm}$ deep rectangular hole and pressed against optically smooth glass plate.

\section{Results and Discussion}

FTIR and NMR spectroscopic analysis

Infrared spectroscopy has proven to be extremely useful in studies of organic compounds, polymer, organic-inorganic silica glass hybrid, pharmaceuticals and petrochemicals. The characteristics IR bands of the chemically blended silica glass are given in Table 1. FTIR spectrum in the range 400$4000 \mathrm{~cm}^{-1}$ has been used as a tool to assign the significant features of the reaction product in comparing them with starting material ${ }^{40}$. The representative set of IR spectra of some selected silica composites are shown in Figure

Table 1 IR spectra of chemically blended silica composite

\begin{tabular}{|l|l|l|l|l|l|l|}
\hline \multirow{2}{*}{$\begin{array}{l}\text { Characteristics } \\
\text { Band }\end{array}$} & \multicolumn{6}{|c|}{ Wave Number $\left(\mathbf{c m}^{-1}\right)$} \\
\cline { 2 - 7 } & $\mathbf{S i O}_{2}$ & $\begin{array}{l}\text { VNY- } \\
\mathbf{S i O}_{2}\end{array}$ & $\begin{array}{l}\text { Ali-SiO } \\
\text { 2 }\end{array}$ & $\begin{array}{l}\text { MMA- } \\
\mathbf{S i O}_{2}\end{array}$ & $\begin{array}{l}\text { NAP- } \\
\mathbf{S i O}_{2}\end{array}$ & Remarks \\
\hline Si-OH & 3741.68 & 3852.37 & 3741.30 & & 3763.19 & Broad O-H \\
\hline
\end{tabular}




\begin{tabular}{|c|c|c|c|c|c|c|}
\hline $\mathrm{O}-\mathrm{H}$ & $\begin{array}{l}3670.78 \\
3531.98 \\
--\end{array}$ & $\begin{array}{l}-- \\
3461.65 \\
2357.06\end{array}$ & 3440.56 & $\begin{array}{l}3406.45 \\
2361.57 \\
2109.74\end{array}$ & 3448.04 & Hydrogen bonded $\mathrm{O}-\mathrm{H}$ \\
\hline $\begin{array}{l}\mathrm{C}=\mathrm{C} \text { str.or the } \\
\text { silica over tone } \\
\text { band. }\end{array}$ & & 1646.93 & 1644.86 & 1647.16 & 1646.74 & \\
\hline $\begin{array}{l}\mathrm{C}=\mathrm{O} \text { str of six } \\
\text { membered ring }\end{array}$ & & & 1541.18 & & $\begin{array}{l}1539.25 \\
1502.58\end{array}$ & \\
\hline $\begin{array}{l}\text { C-O str band } \\
\text { Si-O-Si and Si- } \\
\text { O-C }\end{array}$ & 1070.31 & 1093.45 & $\begin{array}{l}1132.56 \\
1074.56\end{array}$ & $\begin{array}{l}1384.53 \\
1073.98\end{array}$ & 1074.17 & $\begin{array}{l}\text { Asymmetric Si-O-C } \\
\text { and } \mathrm{Si}-\mathrm{O}-\mathrm{Si} \text { absorbs in } \\
\text { the same region, with } \\
\text { increase in chain } \\
\text { length intensity } \\
\text { increases. }\end{array}$ \\
\hline Si-OR & & 856.26 & 932.61 & $\begin{array}{l}742.15 \\
663.83 \\
619.86\end{array}$ & $\begin{array}{l}862.29 \\
795.53 \\
666.92\end{array}$ & \\
\hline
\end{tabular}
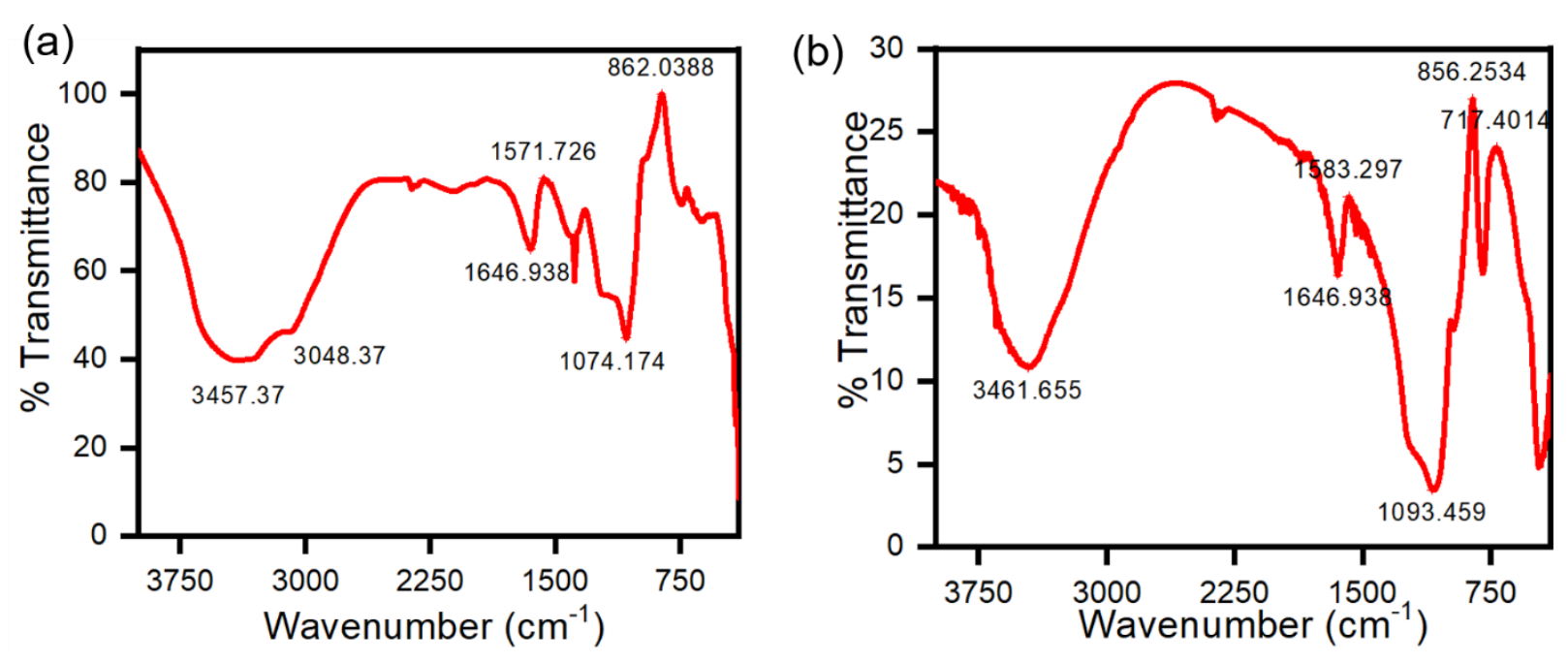

Figure 1. IR spectrum of (a) $\mathrm{NAP}-\mathrm{SiO}_{2}$ composite and (b) $\mathrm{VIN}-\mathrm{SiO}_{2}$ glass 
The most significant features of the inorganic component of these silica composites are that the $\mathrm{Si}-\mathrm{O}-\mathrm{Si}$ and $\mathrm{Si}-\mathrm{O}-\mathrm{C}$ bands appeared at their normal positions. The aforementioned stretching bands appeared at $1070.31 \mathrm{~cm}^{-1}\left(\mathrm{SiO}_{2}\right), 1093.45 \mathrm{~cm}^{-1}\left(\mathrm{PVNY}-\mathrm{SiO}_{2}\right), 1074.56 \mathrm{~cm}^{-1}\left(\mathrm{Ali}-\mathrm{SiO}_{2}\right), 1073.98$ $\mathrm{cm}^{-1}$ (MMA-SiO 2$), 1074.17 \mathrm{~cm}^{-1}\left(\mathrm{NAP}-\mathrm{SiO}_{2}\right)$. The strong O-H stretching vibration of Si-OH group absorbs in the same region as that of alcohol, i.e., at $3700-3200 \mathrm{~cm}^{-1}$. The $\mathrm{C}=\mathrm{C}$ stretching band found at $1644-1647 \mathrm{~cm}^{-1}$ for all the composites except the silica composite made from pure TEOS. The $\mathrm{C}=\mathrm{O}$ stretching band appeared at $1541.18 \mathrm{~cm}^{-1}$ for ALI-SiO2 composite and at $1539.53 \mathrm{~cm}^{-}$ ${ }^{1}$ for NAP- $\mathrm{SiO}_{2}$ composite. However, a comparison of the assignments for each spectrum showed no significant differences.

The NMR characterization data of these compounds is summarized in Table 2

\begin{tabular}{|c|c|}
\hline Compound & NMR Characteristics (CDCl3, $200 \mathrm{MHz})$ \\
\hline $\begin{array}{l}\text { Poly vinyl triethoxy silane } \\
-[-\mathrm{CH}_{2}-\underbrace{\mathrm{CH}}_{\mathrm{Si}(\mathrm{OEt})_{3}} \cdot]_{\mathrm{n}}\end{array}$ & $1.17-1.33$ (br t), $3.40-3.85$ (br q) \\
\hline Allylated napthol & $\begin{array}{l}\text { 4.59-4.62(m, 2H),5.96-6.12(m, 1H), } 6.18(\mathrm{~s}, 1 \mathrm{H}), 7.66- \\
7.79(\mathrm{~m}, 2 \mathrm{H}), 8.05-8.15(\mathrm{~m}, 2 \mathrm{H})\end{array}$ \\
\hline Hydrosilylated napthol & $\begin{array}{l}1.07(\mathrm{t}, 3 \mathrm{H}), 1.53(\mathrm{t}, 2 \mathrm{H}) 1.81-1.95(\mathrm{~m}, 3 \times 2 \mathrm{H}), 3.96(\mathrm{t}, \\
2 \mathrm{H} \mathrm{J}=6.63 \mathrm{~Hz}) 4.07(\mathrm{bq}, 3 \times 2 \mathrm{H}), 6.14(\mathrm{~s}, 1 \mathrm{H}), 7.69- \\
7.74(\mathrm{~m}, 2 \mathrm{H}), 8.04-8.10(\mathrm{~m}, 2 \mathrm{H})\end{array}$ \\
\hline
\end{tabular}




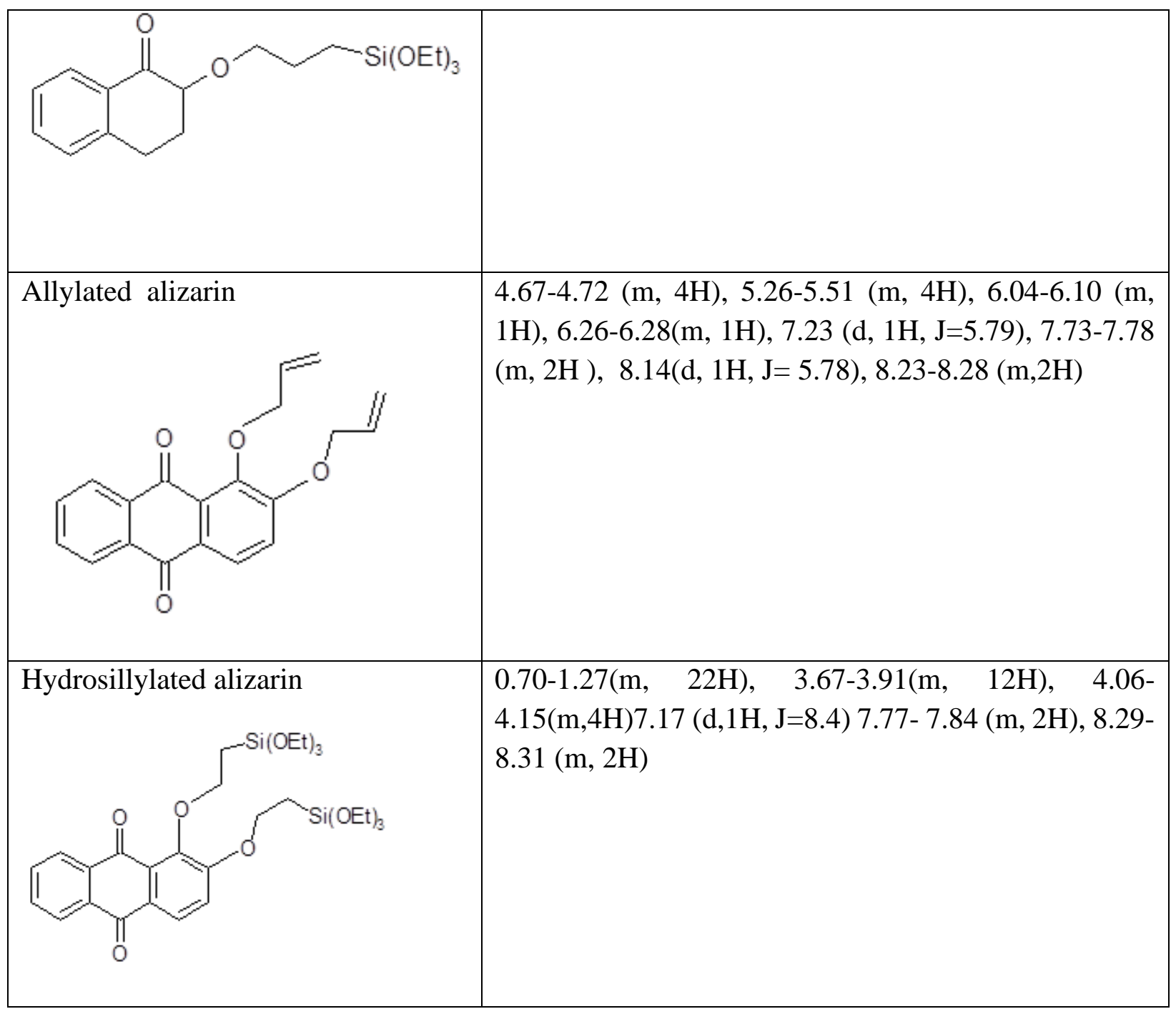

\section{Thermal analysis}

Thermal analysis diagrams, shown in Figures 3a-b and 4 a-d were used to study the thermal stability of the chemically blended silica composites. Thermal analysis diagram had been collected to study the changes of inorganic-organic hybrid glass with thermal treatment. The results are presented in Table 2. Each TGA diagram exhibited three weight loss stages though the onset of decomposition temperature was slightly different from one another. 
(a)

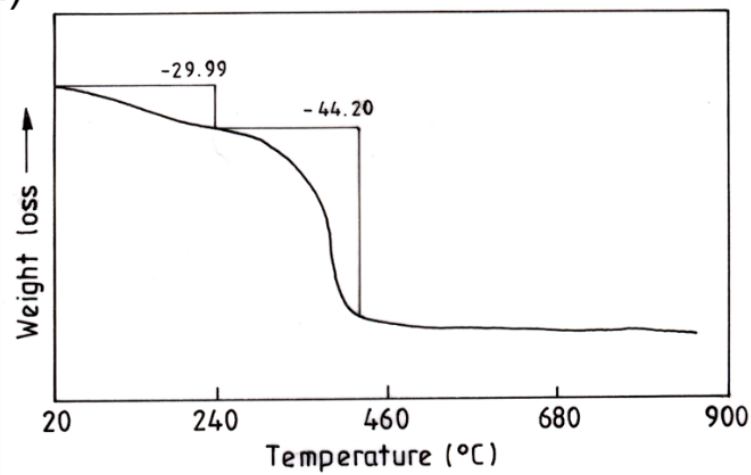

(b)

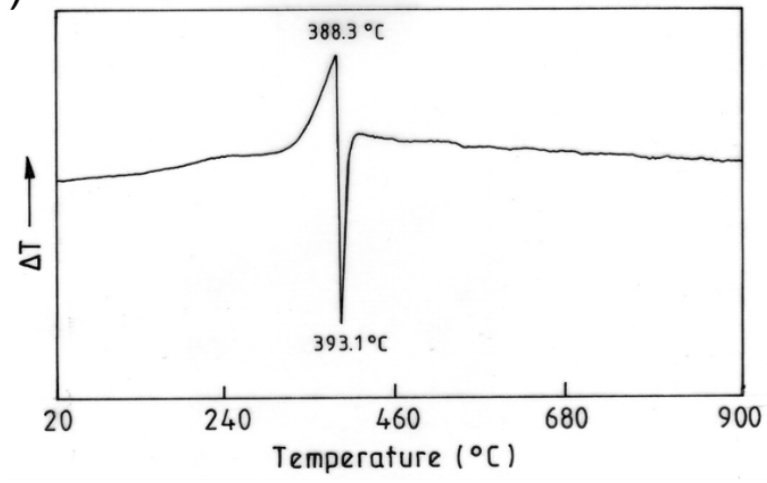

Figure 3(a-b). TGA -DTG diagram of VNY-SiO 2 composite

Table 2 Thermal analysis diagram of chemically blended silica glass

\begin{tabular}{|c|c|c|c|c|c|c|c|c|c|}
\hline \multirow{3}{*}{$\begin{array}{l}\text { Sample } \\
\text { designation }\end{array}$} & \multicolumn{9}{|c|}{ Decomposition temperature $\left(0^{0} \mathrm{C}\right)$} \\
\hline & \multicolumn{3}{|c|}{ First stage } & \multicolumn{3}{|c|}{ Second stage } & \multicolumn{3}{|c|}{ Third Stage } \\
\hline & Initial & Final & $\begin{array}{l}\text { Mass } \\
\text { loss (\%) }\end{array}$ & Initial & Final & $\begin{array}{l}\text { Mass } \\
\text { loss (\%) }\end{array}$ & Initial & Final & $\begin{array}{l}\text { Mass } \\
\text { loss } \\
(\%)\end{array}$ \\
\hline $\mathrm{VNY}-\mathrm{SiO}_{2}$ & 30 & 240 & 29 & 240 & 440 & 44 & 440 & 680 & 2 \\
\hline MMA-SiO 2 & 29 & 153 & 8 & 153 & 417 & 36 & 417 & 501 & 1 \\
\hline NAP-SiO ${ }_{2}$ & 82 & 130 & 55 & 130 & 710 & 26 & 587 & 997 & 17 \\
\hline $\begin{array}{l}\text { Chem-ALI- } \\
\mathrm{SiO}_{2}\end{array}$ & 95 & 200 & 15 & 200 & 587 & 23 & 684 & 990 & 2 \\
\hline $\mathrm{SiO}_{2}$ & 58 & 225 & 18 & 225 & 684 & 28 & -- & -- & --- \\
\hline
\end{tabular}
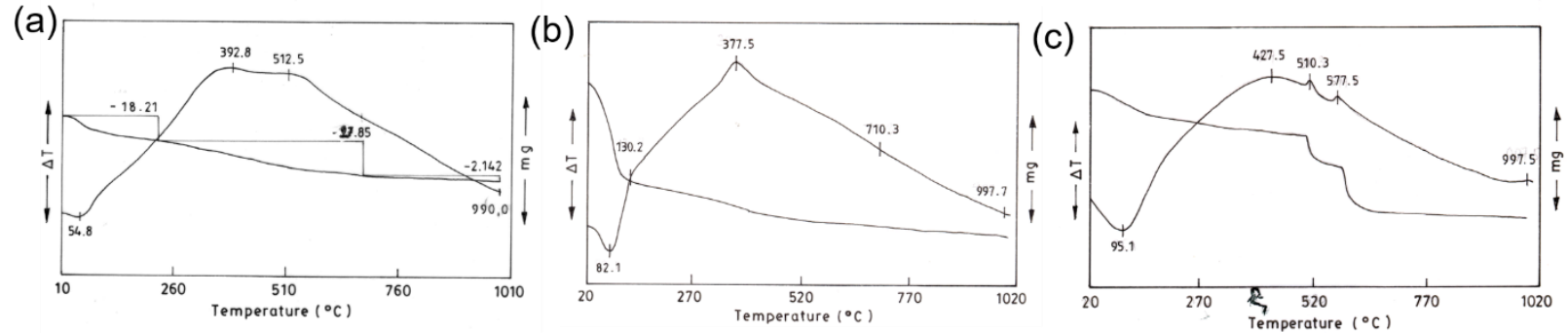
Figure 4 Thermal diagram of (a) $\mathrm{SiO}_{2}$ glass, (b) $\mathrm{NAP}_{-} \mathrm{SiO}_{2}$ composite and (c) Chem-ALI-SiO 2 composite

The differences could be attributed to the presence of different organic molecules. A gradual weight loss occurred below $250{ }^{\circ} \mathrm{C}$. Mass loss was less than $30 \%$ in most of the cases. The weight loss was due to evaporation of water and volatilization and thermal decomposition of the trapped organic solvent. Since in this process gelling and condensation were performed at ambient atmosphere a greater amount of solvent and water molecules got trapped in these composites. It was seen from the TGA profiles of NAP-SiO 2 composite that it exhibited 59\% weight loss in the first stage (22.4-130 $\left.{ }^{\circ} \mathrm{C}\right)$. From the DTG curve a corresponding endothermic peak was observed at 82.1 ${ }^{\circ} \mathrm{C}$. It might be due to the evaporation of the trapped solvent (THF and ethanol). But in all other cases major weight loss occurred during the second degradation stage. This could be attributed to the thermal decomposition of the organic moiety. DTG curve showed an exothermic peak at this temperature range $\left(150-600{ }^{\circ} \mathrm{C}\right)$. It was believed that exothermic peaks arise due to restructuring during crystallization process and oxidation of the organic matrix ${ }^{41,42}$. It was evident that the oxidation of the organic molecules coming from the dye or polymer occurred at higher temperature. Such exothermic peaks were absent in the case of samples prepared without polymer. The location of the peak and their relative position depend on the structural properties of the gel ${ }^{43}$. In case of alizarin composite the $2-3 \%$ weight loss occurred in the final stage of decomposition. After the loss of organic component, the TGA curves became flat up to $900^{\circ} \mathrm{C}$ with only inorganic material remaining.

Comparison of thermal stability between physically and chemically blended. silica glass. Table 3 Thermal stability of physically and chemically blended silica glass composites

\begin{tabular}{|c|c|c|c|c|c|c|c|c|c|}
\hline \multirow[t]{3}{*}{ Sample designation } & \multicolumn{9}{|c|}{ Decomposition temperature $\left(0^{\circ} \mathrm{C}\right)$} \\
\hline & \multicolumn{3}{|c|}{ First stage } & \multicolumn{3}{|c|}{ Second stage } & \multicolumn{3}{|c|}{ Third stage } \\
\hline & Initial & Final & $\begin{array}{c}\text { Mass } \\
\text { loss } \\
(\%)\end{array}$ & Initial & Final & $\begin{array}{c}\text { Mass } \\
\text { loss }(\%)\end{array}$ & Initial & Final & $\begin{array}{l}\text { Mass loss } \\
(\%)\end{array}$ \\
\hline Phy-Ali-SiO 2 & 23 & 112 & 56 & 112 & 645 & 32 & 645 & 997 & 1 \\
\hline
\end{tabular}


We discussed the preparation and properties of physically blended alizarin-silica composites. Here we deal with chemically blended alizarin-silica composites. For these composites we have selected alizarin as one of the starting materials for preparation of both physically and chemically blended silica composites. It has been reported that physically blended alizarin and silica glass disintegrates through crack formation during slow drying of the gel. Although initially a homogenous blend of alizarin in THF and aqueous TEOS was formed but during drying by evaporation of solvents alizarin was separated into a discrete phase apart from disintegration of the glass. Therefore, we thought that if alizarin could be chemically bound to $\mathrm{SiO}_{2}$ matrix, probably those drawbacks of phase separation and cracking could be overcome. In order to chemically bind alizarin to silica it was first fictionalized through allylation of its hydroxyl group followed by hydrosilylation of the allyl group. Then this functionalized alizarin was simultaneously hydrolyzed and co-condensed with TEOS. Thus, the alizarin molecule becomes chemically bonded through the allyl group to $\mathrm{SiO}_{2}$ matrix. The sequences of reactions of alizarin and TEOS are shown in Scheme 4. It was well known that acid catalyzed glass formation by hydrolysis of TEOS was a slow process during which time a three-dimensional network of glass was formed with slow evaporation of solvent. In absence of chemical linkage of alizarin to silica a mechanical stress was developed due to shrinkage of glass network by the evaporation of the solvent. As such the silica network was rigid and alizarin also contains two benzene rings fused to an anhydride ring making it highly rigid. Therefore, both alizarin and silica being rigid form a highly amorphous and brittle three-dimensional structure and expulsion of solvent from the swelled hydrogel force the gel network to collapse. On the contrary, when alizarin was chemically linked through a $-\mathrm{CH}_{2}-\mathrm{CH}_{2}-$ bridge to $\mathrm{SiO}_{2}$ the gel did not collapse and crack after evaporation of solvent. This observation occurred due to the flexible $-\mathrm{CH}_{2}-\mathrm{CH}_{2}$ - linkage that prevented the gel from cracking.

The results of the comparative study with these composites are given in Table.3. It was observed that stability of chemically blended alizarin composite (Chem-Ali- $\mathrm{SiO}_{2}$ ) was higher than that of physically blended (Phy-Ali-SiO 2$)$ one. Thermal diagram indicated that both composites exhibited three stages of decomposition. Initial decomposition took place within the temperature region $22^{\circ} \mathrm{C}-200^{\circ} \mathrm{C}$. In case of physically blended (Phy-Ali-SiO 2$)$ silica glass $56.8 \%$ weight loss 
has been taken place in the first stage. On the other hand, chemically blended silica composite exhibited $15 \%$ weight loss during the initial stage of decomposition. It also indicated greater degree of condensation during the preparation of chemically blended silica glass. During second stage of decomposition both the composites exhibited comparable mass loss. In this stage mass loss occurred due to the decomposition of organic component. Total weight loss in case of former composite was $90.56 \%$ whereas for the latter case it was $54.56 \%$. From the result it was clear that chemically blended silica glass exhibited greater thermal stability.

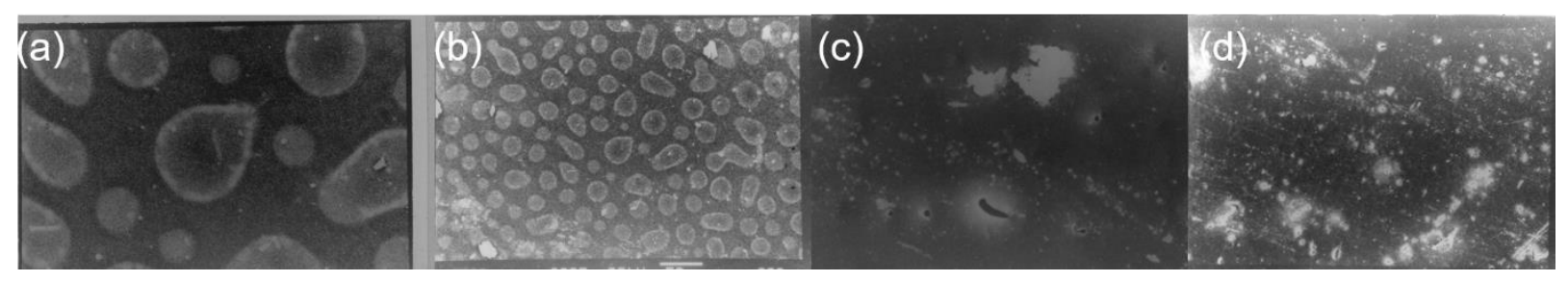

Figure 5 SEM micrographs of (a-b) silica composite, (c) $\mathrm{NAP}-\mathrm{SiO}_{2}$ composite (d) $\mathrm{ALI}-\mathrm{SiO}_{2}$ composite

The scanning electron micrographs revealed some interesting morphological differences between the $\mathrm{SiO}_{2}$ prepared from TEOS and different chemically blended silica composites. Figure 4a represented SEM micrographs of silica glass prepared from TEOS. Particles of different shapes and sizes are observed in the Figure 5a. Figures 5 (c-d) represented SEM micrographs of chemically blended silica glass hybrids like $\mathrm{Nap}-\mathrm{SiO}_{2}$ and $\mathrm{Chem}-\mathrm{Ali}-\mathrm{SiO}_{2}$. It was observed that the particles appeared to be more densely packed with relatively smaller size. It was quite different from that of the Figure 5a. But the general morphological feature of various chemically blended silica composites was not different from one another, non-uniform particle distribution was the conspicuous feature.

\section{Hydrolytic stability}

One of the big problems of unmodified $\mathrm{SiO}_{2}$ gels, in particular for technical use is their long -term stability under humid atmosphere. Owing to large number of silane groups on the inner surface of the material, adsorption and capillary condensation of water may cause cracking of the composite. 
Water absorption characteristics of chemically modified silica glass after 7 days immersion in water at room temperature are shown in Figure 6. Comparison of water uptake exhibited that highest water absorption takes place in case of napthol composite (NAP-SiO 2$)$.

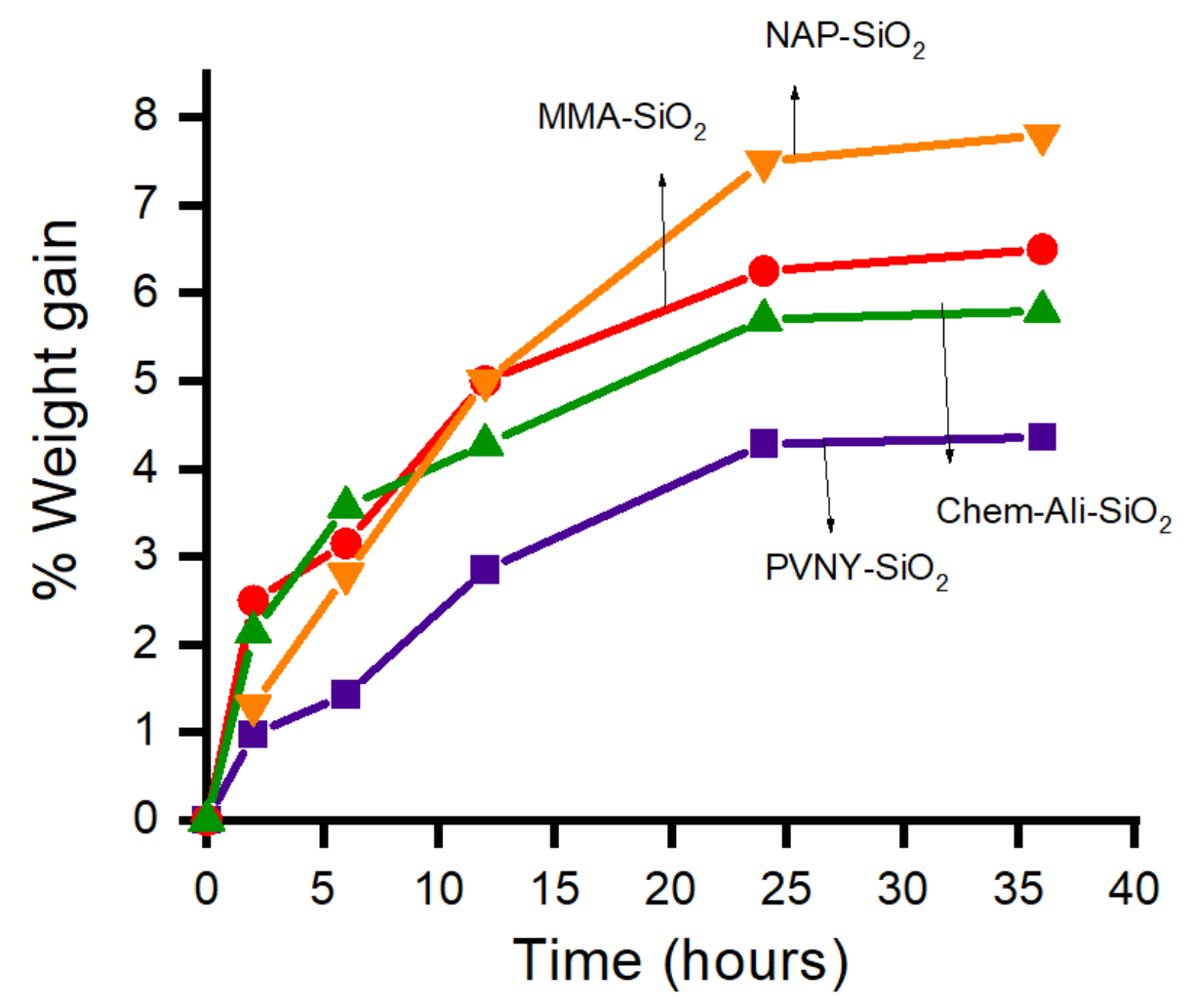

Figure 6. Water absorption studies of chemically blended silica glasses

It is well known that water absorption takes place either by capillary action through void space or by H-bonding with the polar part of the molecule. Hence, with increase in void space or polar functional group water absorption increases. In napthol-silica composite due to monoallylation less cross-linking occurred, and greater void space may remain in the final hybrid composite. This may be the reason of higher water up take. In $\mathrm{MMA}-\mathrm{SiO}_{2}$ composite besides the void space, polar $\mathrm{OCH}_{3}$ group may be responsible for water absorption by hydrogen bonding. In chemically blended alizarin composite and $\mathrm{PVNY}-\mathrm{SiO}_{2}$ composite water absorption was quite low due to greater cross linking.

\section{Stability in acid}

Table 4 Acid Stability of chemically blended silica glass 


\begin{tabular}{|l|l|l|l|}
\hline Sample & $2 \mathrm{hr}$ & $24 \mathrm{hr}$ & 7 days \\
\hline & & & \\
PVNY-Si & 0.0 & 4.5 & 4.5 \\
PMMA-Si & 0.0 & 0.0 & 5.9 \\
NAP-Si & 0.0 & 0.0 & 0.0 \\
ALI -Si & 0.0 & 0.0 & broken \\
\hline
\end{tabular}

The resistance of prepared chemically blended glasses towards different concentration of mineral acid like $\mathrm{HCl}$ was studied. It was observed from Table 4 that weight loss of different composite was negligible in acid medium. But only chemically blended alizarin composite was broken. This was due to breakage of hydrolysable linkage. The good stability of other silica composite in acid medium of was due to non-hydrolysable linkage. This was also an indication of larger degree of polycondensation.

\section{X-Ray diffraction analysis}

Microstructure of the porous chemically blended silica composites were investigated by X-Ray diffraction (Figure 7). All the composites are amorphous.

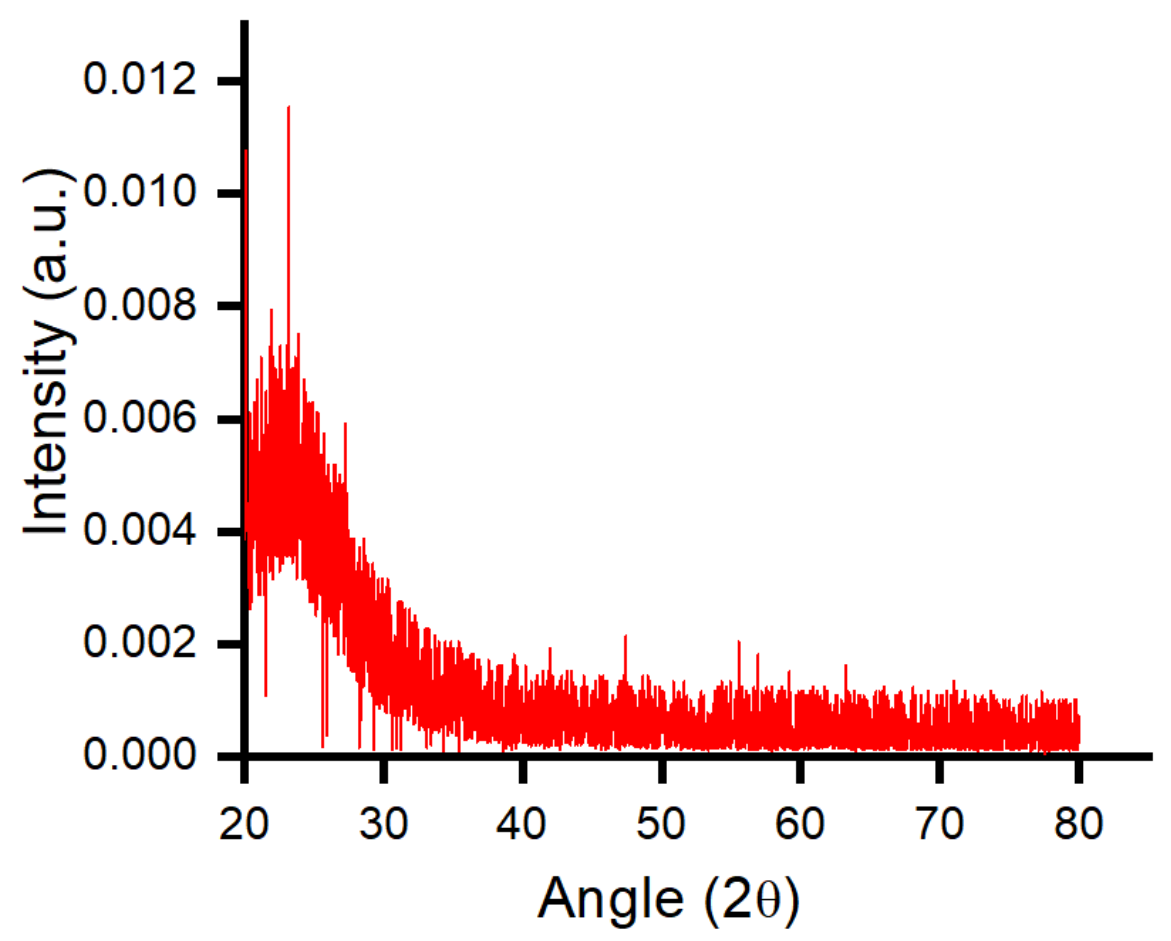


Figure 7. X-Ray diffraction profile of $\mathrm{Ali}-\mathrm{SiO}_{2}$ Composite

\section{Conclusion}

We have synthesized chemically blended hybrid glass, in which polymer molecule or monomer molecule are uniformly distributed and covalently bonded to inorganic matrices. We studied all the glass composites by IR, TGA and SEM etc. experiments. All hybrid composites present a good thermal stability, water resistance and good stability in acid solution. It is clear from literature survey that sol-gel processing has huge potential to produce a wide range of specialized products in established composition as well as novel composition not readily accessible by conventional manufacturing techniques.

\section{References}

1. Sakka, S.; Kamiya, K., The sol-gel transition in the hydrolysis of metal alkoxides in relation to the formation of glass fibers and films. Journal of Non-Crystalline Solids 1982, 48 (1), 31-46.

2. Ward, D. A.; Ko, E. I., Preparing Catalytic Materials by the Sol-Gel Method. Industrial \& Engineering Chemistry Research 1995, 34 (2), 421-433.

3. Mann, S.; Burkett, S. L.; Davis, S. A.; Fowler, C. E.; Mendelson, N. H.; Sims, S. D.; Walsh, D.; Whilton, N. T., Sol-Gel Synthesis of Organized Matter. Chemistry of Materials 1997, 9 (11), 2300-2310.

4. Ray, P.; Ferraro, M.; Haag, R.; Quadir, M., Dendritic Polyglycerol-Derived NanoArchitectures as Delivery Platforms of Gemcitabine for Pancreatic Cancer. Macromol Biosci 2019, 19 (7), e1900073.

5. Ray, P.; Haideri, N.; Haque, I.; Mohammed, O.; Chakraborty, S.; Banerjee, S.; Quadir, M.; Brinker, A. E.; Banerjee, S. K., The Impact of Nanoparticles on the Immune System: A Gray Zone of Nanomedicine. Journal of Immunological Sciences 2021, 5 (1).

6. Ray, P.; Dutta, D.; Haque, I.; Nair, G.; Mohammed, J.; Parmer, M.; Kale, N.; Orr, M.; Jain, P.; Banerjee, S.; Reindl, K. M.; Mallik, S.; Kambhampati, S.; Banerjee, S. K.; Quadir, M., 
pH-Sensitive Nanodrug Carriers for Codelivery of ERK Inhibitor and Gemcitabine Enhance the Inhibition of Tumor Growth in Pancreatic Cancer. Molecular Pharmaceutics 2021, 18 (1), 87-100. 7. Ray, P.; Kale, N.; Quadir, M., New side chain design for pH-responsive block copolymers for drug delivery. Colloids and Surfaces B: Biointerfaces 2021, 200, 111563.

8. Clément, M.; Abdellah, I.; Ray, P.; Martini, C.; Coppel, Y.; Remita, H.; Lampre, I.; Huc, V., Synthesis and NMR study of trimethylphosphine gold(i)-appended calix[8]arenes as precursors of gold nanoparticles. Inorganic Chemistry Frontiers 2020.

9. Abdullah, C. S.; Ray, P.; Alam, S.; Kale, N.; Aishwarya, R.; Morshed, M.; Dutta, D.; Hudziak, C.; Banerjee, S. K.; Mallik, S.; Banerjee, S.; Bhuiyan, M. S.; Quadir, M., Chemical Architecture of Block Copolymers Differentially Abrogate Cardiotoxicity and Maintain the Anticancer Efficacy of Doxorubicin. Molecular Pharmaceutics 2020, 17 (12), 4676-4690.

10. Confeld, M. I.; Mamnoon, B.; Feng, L.; Jensen-Smith, H.; Ray, P.; Froberg, J.; Kim, J.; Hollingsworth, M. A.; Quadir, M.; Choi, Y.; Mallik, S., Targeting the tumor core: hypoxiaresponsive nanoparticles for delivery of chemotherapy to pancreatic tumors. Molecular Pharmaceutics 2020.

11. Sarker, N. C.; Ray, P.; Pfau, C.; Kalavacharla, V.; Hossain, K.; Quadir, M., Development of Functional Nanomaterials from Wheat Bran Derived Arabinoxylan for Nucleic Acid Delivery. Journal of Agricultural and Food Chemistry 2020, 68 (15), 4367-4373.

12. Ray, P.; Nair, G.; Ghosh, A.; Banerjee, S.; Golovko, M. Y.; Banerjee, S. K.; Reindl, K. M.; Mallik, S.; Quadir, M., Microenvironment-sensing, nanocarrier-mediated delivery of combination chemotherapy for pancreatic cancer. Journal of Cell Communication and Signaling 2019.

13. Ray, P.; Alhalhooly, L.; Ghosh, A.; Choi, Y.; Banerjee, S.; Mallik, S.; Banerjee, S.; Quadir, M., Size-Transformable, Multifunctional Nanoparticles from Hyperbranched Polymers for Environment-Specific Therapeutic Delivery. ACS Biomaterials Science \& Engineering 2019, 5 (3), 1354-1365.

14. Ray, P.; Clément, M.; Martini, C.; Abdellah, I.; Beaunier, P.; Rodriguez-Lopez, J.-L.; Huc, V.; Remita, H.; Lampre, I., Stabilisation of small mono- and bimetallic gold-silver nanoparticles using calix[8]arene derivatives. New Journal of Chemistry 2018, 42 (17), 1412814137.

15. Ray, P.; Confeld, M.; Borowicz, P.; Wang, T.; Mallik, S.; Quadir, M., PEG-b-poly (carbonate)-derived nanocarrier platform with $\mathrm{pH}$-responsive properties for pancreatic cancer combination therapy. Colloids Surf B Biointerfaces 2018, 174, 126-135.

16. Jayanta, R.; Leena, B., Preparation and Evaluation of Novel Bamboo-Polymer Composites. 2021.

17. Ray, P.; Gidley, D.; Badding, J. V.; Lueking, A. D., UV and chemical modifications of polymer of Intrinsic Microporosity 1 to develop vibrational spectroscopic probes of surface chemistry and porosity. Microporous and Mesoporous Materials 2019, 277, 29-35.

18. Ray, J. K.; Singha, R.; Ray, D.; Ray, P.; Rao, D. Y.; Anoop, A., Palladium-catalyzed expedient Heck annulations in 1-bromo-1,5-dien-3-ols: Exceptional formation of fused bicycles. Tetrahedron Letters 2019, 60 (13), 931-935.

19. Ray, P.; Xu, E.; Crespi, V. H.; Badding, J. V.; Lueking, A. D., In situ vibrational spectroscopy of adsorbed nitrogen in porous carbon materials. Physical Chemistry Chemical Physics 2018, 20 (22), 15411-15418.

20. Ray, J. K.; Paul, S.; Ray, P.; Singha, R.; Rao, D. Y.; Nandi, S.; Anoop, A., Pd-catalyzed intramolecular sequential Heck cyclization and oxidation reactions: a facile pathway for the 
synthesis of substituted cycloheptenone evaluated using computational studies. New Journal of Chemistry 2017, 41 (1), 278-284.

21. Chaudhuri, S.; Maity, S.; Roy, M.; Ray, P.; Ray, J. K., A Vinyl Radical Cyclization Route to Hydroxycyclohexene Fused Carbocycles. Asian Journal of Chemistry 2016, 28 (1).

22. Ray, P.; Gray, J. L.; Badding, J. V.; Lueking, A. D., High-Pressure Reactivity of Triptycene Probed by Raman Spectroscopy. The Journal of Physical Chemistry B 2016, 120 (42), 11035-11042.

23. Ray, P., Interactions of nitrogen and hydrogen with various $1 \mathrm{D}$ and 3D carbon materials probed via in-situ vibrational spectroscopy. Ph. D. Thesis 2016.

24. Wang, C.-Y.; Ray, P.; Gong, Q.; Zhao, Y.; Li, J.; Lueking, A. D., Influence of gas packing and orientation on FTIR activity for $\mathrm{CO}$ chemisorption to the $\mathrm{Cu}$ paddlewheel. Physical Chemistry Chemical Physics 2015, 17 (40), 26766-26776.

25. Brahma, S.; Ray, P.; Singha, R.; Ray, J. K., Visible Colourimetric and Ratiometric Fluorescent Chemosensors for $\mathrm{Cu}$ (II) and Ni (II) Ions. Asian Journal of Chemistry 2016, 28 (5), 1035 .

26. Singha, R.; Roy, S.; Nandi, S.; Ray, P.; Ray, J. K., Palladium-catalyzed one-pot SuzukiMiyaura cross coupling followed by oxidative lactonization: a novel and efficient route for the one-pot synthesis of benzo[c]chromene-6-ones. Tetrahedron Letters 2013, 54 (7), 657-660.

27. Ray, D.; Nasima, Y.; Sajal, M. K.; Ray, P.; Urinda, S.; Anoop, A.; Ray, J. K., PalladiumCatalyzed Intramolecular Oxidative Heck Cyclization and Its Application toward a Synthesis of ( \pm - $\beta$-Cuparenone Derivatives Supported by Computational Studies. Synthesis 2013, 45 (09), 1261-1269.

28. André, E.; Boutonnet, B.; Charles, P.; Martini, C.; Aguiar-Hualde, J. M.; Latil, S.; Guérineau, V.; Hammad, K.; Ray, P.; Guillot, R.; Huc, V., A New, Simple and Versatile Strategy for the Synthesis of Short Segments of Zigzag-Type Carbon Nanotubes. Chemistry 2016, 22 (9), 3105-14.

29. Parkhurst, C. S.; Doyle, W. F.; Silverman, L. A.; Singh, S.; Andersen, M. P.; McClurg, D.; Wnek, G. E.; Uhlmann, D. R., Siloxane Modified SiO2-TiO2 Glasses via Sol-Gel. MRS Online Proceedings Library 1986, 73 (1), 769-773.

30. Bates, F. S., Block copolymers near the microphase separation transition. 2. Linear dynamic mechanical properties. Macromolecules 1984, 17 (12), 2607-2613.

31. Glaser, R. H.; Wilkes, G. L., Structure property behavior of polydimethylsiloxane and poly(tetramethylene oxide) modified TEOS based sol-gel materials. Polymer Bulletin 1988, 19 (1), 51-57.

32. Lebeau, B.; Sanchez, C., Sol-gel derived hybrid inorganic-organic nanocomposites for optics. Current Opinion in Solid State and Materials Science 1999, 4 (1), 11-23.

33. Wang, B.; Wilkes, G. L.; Hedrick, J. C.; Liptak, S. C.; McGrath, J. E., New highrefractive-index organic/inorganic hybrid materials from sol-gel processing. Macromolecules 1991, 24 (11), 3449-3450.

34. Calvert, P., Vegetable and mineral. Nature 1991, 353 (6344), 501-502.

35. Pope, E. J. A.; Asami, M.; Mackenzie, J. D., Transparent silica gel-PMMA composites. Journal of Materials Research 1989, 4 (4), 1018-1026.

36. Schmidt, H., Organic modification of glass structure new glasses or new polymers? Journal of Non-Crystalline Solids 1989, 112 (1), 419-423. 
37. Tsumura, M.; Ando, K.; Kotani, J.; Hiraishi, M.; Iwahara, T., Silicon-Based Interpenetrating Polymer Networks (IPNs): Synthesis and Properties. Macromolecules 1998, 31 (9), 2716-2723.

38. Novak, B. M.; Davies, C., "Inverse" organic-inorganic composite materials. 2. Free-radical routes into nonshrinking sol-gel composites. Macromolecules 1991, 24 (19), 5481-5483.

39. Yen, W.; Dachuan, Y.; Bakthavatchalam, R., Thermal stability and hardness of new polyacrylate-SiO2 hybrid sol-gel materials. Materials Letters 1992, 13 (4), 261-266.

40. Ebdon, J. R., Principles of polymerization George Odian John Wiley and Sons, Inc., New York, 1991. pp. 768, price E47.50. ISBN 0-471-61020-8. Polymer International 1993, 30 (2), 281281.

41. Lenz, R. W., Experiments in polymer science, Edward A. Collins, Jan Bares, Fred W. Billmeyer, Jr., Wiley-Interscience, New York, 1973. 530 pp. \$16.95. Journal of Polymer Science: Polymer Letters Edition 1974, 12 (9), 535-536.

42. Colby, M. W.; Osaka, A.; Mackenzie, J. D., Effects of temperature on formation of silica gel. Journal of Non-Crystalline Solids 1986, 82 (1), 37-41.

43. Pauthe, M.; Phalippou, J.; Corriu, R.; Leclercq, D.; Vioux, A., Silica xerogels containing a functional group at silicon. Journal of Non-Crystalline Solids 1989, 113 (1), 21-30. 